Article

\title{
Real-Time Control of Urban Water Cycle under Cyber-Physical Systems Framework
}

\author{
Congcong Sun ${ }^{1, *}$, Vicenç Puig ${ }^{1}\left[\right.$ and Gabriela Cembrano ${ }^{1,2}$ \\ 1 Advanced Control Systems Group at the Institut de Robòtica i Informàtica Industrial (CSIC-UPC), Llorens i \\ Artigas, 4-6, 08028 Barcelona, Spain; vicenc.puig@upc.edu (V.P.); cembrano@iri.upc.edu (G.C.) \\ 2 CETaqua, Water Technology Centre, 08904 Barcelona, Spain \\ * Correspondence: csun@iri.upc.edu
}

Received: 6 December 2019; Accepted: 30 January 2020; Published: 3 February 2020

\begin{abstract}
The urban water cycle (UWC), which is composed of the water supply system (WSS) and urban drainage system (UDS), is a critical infrastructure required for the functioning of urban society. Considering the growing pollution and subsequent water scarcity caused by increasing urbanization and climate change, efficient UWC management is required to maintain resource sustainability and environmental protection. Cyber-physical systems (CPSs) provide a technological suite for the efficient management of critical systems. To exploit advantages of CPS for UWC, this paper proposes a CPS-based management framework enabling supervision, subsystem interoperability, and integrated optimization of UWC: (1) Firstly, clear definitions are provided to demonstrate that UWC systems can be considered as CPSs. (2) A multi-layer CPS-based supervision framework is presented afterwards, conceptually dividing the physical UWC and its digital counterpart into Supervision\&Control, Scheduling, Digital Twin, and Water Users and Environment four layers. (3) The information flows that interact with each layer, as well as a key aspect of CSP operation, namely the interoperability among subsystems in the context of UWC, are also addressed. (4) To demonstrate advantages of supervision and interoperability of subsystems under the CPS framework, an integrated optimizer based on model predictive control (MPC) is applied and compared against the individual control of each system. A real case study of the WSS and UDS in Barcelona UWC is applied in order to validate the proposed approaches through virtual reality simulations based on MATLAB/SIMULIN and EPA-SWMM.
\end{abstract}

Keywords: UWC; CPS; supervision; interoperability; integrated optimization; MPC

\section{Introduction}

Water is a vital resource. The regular and reliable supply of water and treatment services in a city are critical for many urban activities [1]. The urban water cycle (UWC) infrastructure, including the water supply system (WSS) and the urban drainage system (UDS), maintain proper water services in a city. However, with increasing urbanization and climate change, water resources and the associated environment are increasingly threatened by water scarcity and pollution problems. To confront this challenge, efficient and reliable management of systems in the UWC is required.

The WSS and UDS are usually operated separately by different water authorities under their respective control objectives [2-7]. Furthermore, these systems are composed of numerous functional subsystems. As presented in Figure 1, in WSS, the Drinking Water Treatment Plant (DWTP) extracts water from the Natural Water Bodies. After that, the drinkable water is delivered to the Water Users through the Drinking Water Delivery and Distribution system (DWDDS). In UDS, especially in the combined UDS (which is the main UDS infrastructure generates pollutions through combined sewer overflows in storm weather), wastewater and storm water are collected through the Wastewater and 
Stormwater Collection Systems (WSCS) and then treated in Wastewater Treatment Plants (WWTP) before they are released to the receiving environment. When the WWTP capacity is exceeded, combined sewer overflow (CSO) occurs [3,8-10]. DWTP, DWDDS, WSCS, and WWTP are functional subsystems that are interconnected and managed by computing and control systems through physical-domain sensors and actuators.

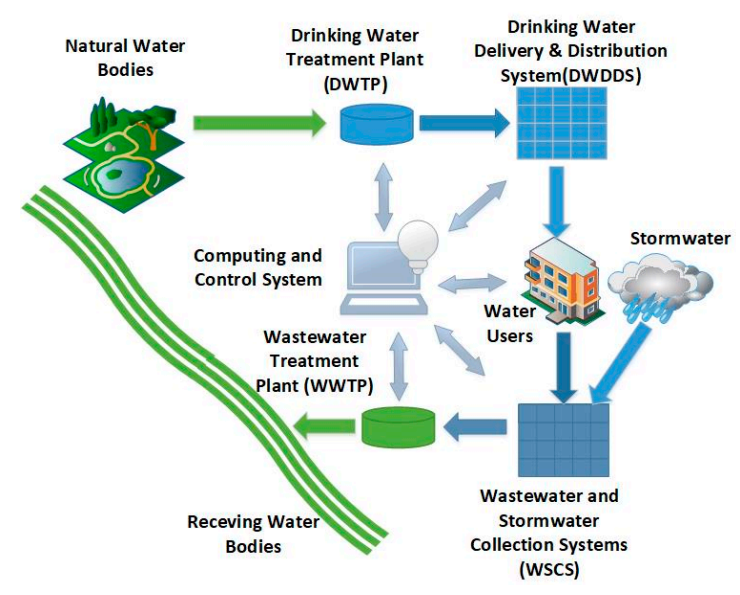

Figure 1. A complete urban water cycle.

The release of CSO may cause significant pollutions and effects for the aquatic ecosystems and human health because of the mix of untreated domestic, commercial, industrial wastewater with storm water runoff [11]. Minimize the pollutions of CSO is the goal for storm water management in many cities with combined sewers. Traditionally, passive approaches were used such as constructing separated sewers, building storage retention tanks with problems in high cost and land availability [12]. Besides, green infrastructure and low impact development (LID) are other options which work well for some case studies [13] but with difficulties for designing standards applicable worldwide.

Cyber-physical systems (CPSs) is an emerging framework with the ability to control the physical system using digital representations due to the development of information and communication technologies (ICT) and digital methodologies. Up to now, there are plenty of research contributions about CPS, e.g., enable smart manufacturing or industrial application by CPS through integrating the virtual computation with physical processes [14-17]. However, there is still lack of a comprehensive contribution with clear explanation and system-wide application details of applying CPS in the water field, which can exploit potential to generate revolutionary change to the UWC. Moreover, there is another concept, the Internet of Things (IoT) which also refers to trends in integrating digital capabilities with physical devices and systems. However, IoT focuses more on simple trackable and/or data objects with limited consideration of system-level control [18]. Under this context, this paper is motivated to propose a CPS-based framework in order to explore innovated technologies to the management of UWC [15].

The WSS and UDS can be considered as CPSs because they contain different components which can be described by a digital representation and interact with the physical world using the embedded sensors, automatic meter reading (AMR) and supervisory control and data acquisition (SCADA) systems. Furthermore, the digital representations can be used to monitor networks and optimize control strategies from a control room, allowing the physical infrastructures to be monitored and controlled through processors and actuators to achieve the desired performance $[10,19]$. The digital representation, also named digital twin [20], of UWC can be developed through high-fidelity simulation platforms, such as SIMULINK/MATLAB, storm water management model (SWMM) [21], MIKE Urban [22], and EPANET [23] etc.

As in all CPS management, the monitoring and control processes for these digital representations are meant to work in real time, with regular interactions between the virtual and physical spaces of the 
systems [10]. Real-time control (RTC) allows the operation of a system to be optimized, including the monitoring of the current system state and the determination of control actions, which are then sent to actuators [24]. RTC is also an efficient approach for storm water control devices [25]. The important nature of RTC means that the management structure of CPS should be able to account for the regular interactions among subsystems and their operational limits in an efficient computation time. This is one of the challenges of implementing CPS for UWC.

Moreover, CPS for UWC is typically designed as a complex network of interacting elements (subsystems). As mentioned above, the subsystems of the UWC are usually managed and operated by different utilities. Additionally, subsystems of CPS may have different individual objectives, which may influence the global performance. The interoperability among different subsystems and the integrated optimization for the supervision of the whole CPS is another challenge [17].

To address these challenges of operating UWC under the CPS context, the main contributions of this work are:

- Definitions illustrating UWC systems as a CPS;

- Development of a multilayer CPS-based supervision framework that conceptually divides the physical UWC and its digital counterpart into four layers (Supervision\&Control Layer, Scheduling Layer, Digital Twin Layer, Water User, and Environment Layer) and definition of the information flows between layers;

- Examination of a key aspect of CPS operation, namely the interoperability among subsystems, in the context of systems in the UWC;

- Demonstration of the advantages of supervision control and interoperability among subsystems of the water cycle with case studies using an integrated optimization approach based on model predictive control (MPC), which improves the reliability and sustainability of the overall control compared with the individual control of both systems.

The remainder of this paper is organized as follows. Section 2 explains the proposed methodologies, which include a multilayer CPS-based supervision management framework, subsystems interoperability and integrated MPC-based optimization algorithm. Section 3 presents the results from case study of the Barcelona UWC to validate the proposed approaches. Finally, Section 4 summarizes the conclusions and presents future research paths.

\section{Materials and Methods}

\subsection{Multilayer CPS-Based Supervision Management Framework}

This section describes a multilayer CPS-based supervision management framework for the digital counterparts (the cyber world) of the physical world. Each layer in the cyber world is corresponding to specific systems in the physical world (as shown in Figure 2).

(1) Supervision\&Control Layer corresponds to the computing and control system in the physical world as presented in Figure 1. In this layer, conceptual models of UWC are used by the advanced control algorithms that provide global strategy by solving an optimal control problem in a timely manner. The control goals are provided by the water users and natural environment (defined in the 4th layer).

(2) Scheduling Layer is in charge of converting the strategies computed by the supervisory control into set-points for specific actuators, through the PLC's (Programable Logic Controller-PLC). Similarly, sensor data are sent to the Supervision\&Control Layer through this layer. Practically, PLCs are flexible and sophisticated enough to run their own control logic, without constantly receiving an input from SCADA. However, this paper discusses advanced global control used in the Supervision\&Control Layer, which generates optimal control actions considering all the subsystems in the CPS. 
(3) The Digital Twin Layer is a digital representation of the physical plant, which uses high fidelity models such as SIMULINK, SWMM, EPANET, and MIKE Urban evaluating the control performance with the desired accuracy. The digital twin may be used to obtain hydraulic or quality variable estimations at locations where no sensors are available. In this sense, they provide extra soft-sensor data, as additional measurements for the upper layers.

(4) Water Users, and Environment Layer. Water users and the environments receive the impact of the control actions in the cyber physical system. Similarly, they define boundary constraints for developing the digital twin and the control goals for the upper control layer. Besides, the impact indicator is generated by the Digital Twin Layer in the format of reliable water service for the water users and environmental influence.

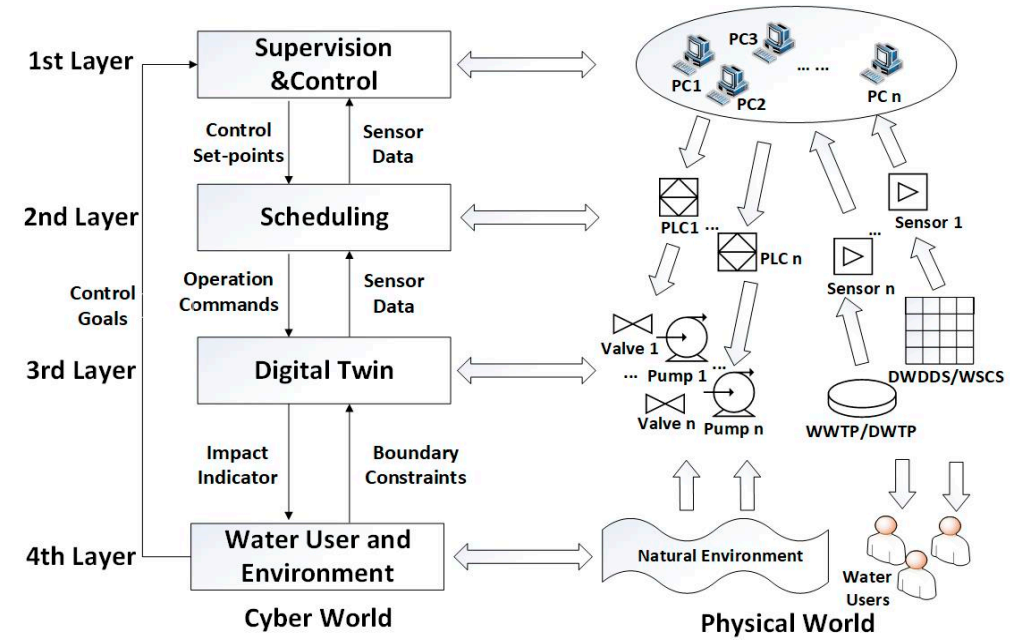

Figure 2. Multilayer cyber-physical system (CPS)-based supervision structure.

\subsection{Interoperability}

Interoperability is a key aspect under CSP operation framework. In the context of UWC, several subsystems are working independently, usually with adequate results for each specific exploitation $[8,26]$. However, addressing the interoperability among subsystems is vital for improving the efficiency of the supervision global management performance.

Interoperability refers to the use of data from one subsystem in processing the supervision control actions of another subsystem. The exchanged information may usually consider outputs of one system as boundary conditions for the next system. CPS should guarantee that the information sets are communicated fluently and the corresponding boundary constraints are updated in a real time manner during the management process for all the subsystems.

Consider the interoperability between WSCS and WWTP as an example (Figure 3). At each time step (e.g., $5 \mathrm{~min}$ ), the WWTP provides the available treatment capacity (information set) to WSCS. This information allows establishing the boundary constraints for the corresponding RTC optimization problem. Then, the WSCS computes the optimal pump flow (information set) and sends this to the WWTP for the next control interval.

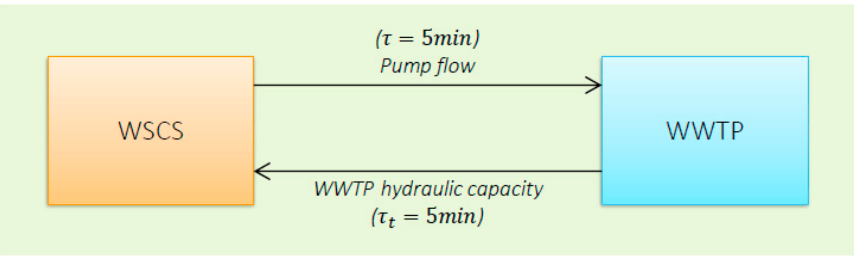

Figure 3. Interoperability between WSCS and wastewater treatment plants (WWTP) in water supply system (WSS). 


\subsection{Integrated MPC-Based Optimization Algorithm}

To demonstrate the advantages of supervision control and interoperability of subsystems, an integrated optimization algorithm is required to compute the optimal operation strategies for the CPS that maximizes the reliability and sustainability of the overall UWC.

MPC is selected as the optimization approach. Already used by many industry sectors, including the water industry [9,26-38], MPC is an efficient control technique for achieving global operational goals in dynamic systems by computing control actions predictively based on a model of the system dynamics, taking into account physical and operational constraints, disturbance predictions, and real-time observations of the system state [26,28,39]. Generally, the MPC method includes prediction optimization based on an internal model and a control formulation of the systems to be controlled. The internal model is usually a simplified discrete model to describe the internal dynamics of the controlled system. The control formulation defines the desired behavior of the controlled system, the optimal behavior, and the length of each prediction.

There have been applications of MPC to UDS, and significant reductions in CSO have been obtained [26,33-35,38,39]. Additionally, MPC-based optimization algorithms have been successfully implemented in WSS subsystems $[31,32,36,37]$ to optimize the water usage or cost produced by electricity consumption. While most MPC applications in UWC management refer to a specific system and its individual operational goals, here we demonstrate the use of MPC in the coordinated (or integrated) management of two (or more) subsystems of the larger UWC system. This integration is related with the concept of supervision control and interoperability in CPS.

The designing of internal models and control formulations of the MPC method are presented in detail in the Sections 2.3.1 and 2.3.2 for the WSS and UDS, respectively.

\subsubsection{Internal Models}

In the WSS, a complete system is generally composed of water tanks to store drinking water from natural sources; a pressurized pipe network to transfer water using valves and/or pumps; and a number of consumer demands $d \in \mathbb{R}^{n_{d}}$. Assuming the stored volumes $\left(m^{3}\right)$ in water tanks $V o l \in \mathbb{R}^{n_{v}}$ are provided by the difference of water inflows Flow in $\in \mathbb{R}^{n_{f i}}\left(\mathrm{~m}^{3} / \mathrm{s}\right)$, outflows Flow out $\in \mathbb{R}^{n_{f o}}\left(\mathrm{~m}^{3} / \mathrm{s}\right)$ and consumer demands $d\left(\mathrm{~m}^{3} / \mathrm{s}\right)$, the conceptual discrete-time model for the water volumes stored in the tanks is presented as:

$$
\operatorname{Vol}(t+1)=\operatorname{Vol}(t)+\Delta t\left(\operatorname{Flow}_{\text {in }}(t)-\text { Flow }_{\text {out }}(t)-d(t)\right)
$$

where $\Delta t \in \mathbb{N}^{+}$is the sampling time and $t \in \mathbb{N}^{+}$is the discrete-time instant. Besides, $n_{d}, n_{v}, n_{f i}, n_{f o}$ are the numbers of consumer demands, tanks, water inflows and outflows, respectively.

Constraints are required for the valve/pump actuators so as to fulfill the lower and upper physical limits:

$$
\underline{\text { Flow }} \leq \text { Flow } \leq \overline{\text { Flow }}
$$

Mass-balance conservation applies to the system nodes where water flows are split and merged:

$$
\sum \text { Flow }_{\text {in }}(t)=\sum \text { Flow }_{\text {out }}(t)
$$

In UDS, the detention tank has a similar hydraulic model as Equation (1). In addition, sewers in a catchment of the UDS have been simplified as virtual tanks that have a storage capacity and a similar hydraulic model as (1). When considering the quality model, detention tanks are important elements for the integrated CPS control, as they store polluted water before it is released into the WWTP with the aim of reducing the pollutant loads when CSO cannot be avoided. To build a quality model for UDS, Total Suspended Solid (TSS) index can be selected as a representative variable because of its correlation with water turbidity, which can be measured online. Simplified TSS models for the sewers 
and junction nodes are created following the procedure presented in [9,40], and the conceptual model for the total mass in the detention tank can be written as:

$$
\operatorname{Mass}(t+1)=(1-e) \operatorname{Mass}(t)+\Delta t\left(\operatorname{Flow}_{\text {in }}(t) T s s_{\text {in }}(t)-\operatorname{Flow}_{\text {out }}(t) \operatorname{Tss}_{\text {out }}(t)\right)
$$

where Mass $\in \mathbb{R}^{n_{m}}(\mathrm{mg})$ represents the total mass in the detention tank; Tss in $\in \mathbb{R}^{n_{\text {ti }}}$ and Tss out $\in \mathbb{R}^{n_{\text {to }}}$ are the TSS inputs and outputs $(\mathrm{mg} / \mathrm{L})$ for the detention tank; $e \in \mathbb{R}$ is the coefficient parameter which needs to be calibrated in the range of $[-1,1]$ (represents sedimentation when $e$ is positive and represents erosion effects when $e$ is a negative number). Besides, $n_{m}, n_{t i}, n_{t o}$ are the numbers of detention tanks, TSS inflows and outflows, respectively. Calibration of the parameter $e$ is executed using measurements generated through virtual reality simulation in SWMM. Details about the calibration processes can be referred from [9].

\subsubsection{Control Formulation}

There are two MPC controllers being developed in this paper, one for WSS and another for UDS. The two MPC controllers are computed and optimized independently. Considering the MPC design, the development of MPC controller for the WSS is based on solving the following optimization problem $[9,27,28,39]$ :

$$
\begin{gathered}
\min _{x, u} J_{W S S}(x, u, w) \\
\text { s.t. } \\
x(t+1)=f_{\text {WSS }}(x(t), u(t), w(t))
\end{gathered}
$$

where the state variable $\mathrm{x} \in \mathbb{R}^{n_{v}}$ represents tank volumes; the control variable $u \in \mathbb{R}^{n_{u v}}$ manipulates flows through the available actuators ( $n_{u w}$ equals with $\left.0.5 * n_{f i}+0.5 * n_{f o}\right)$; and the disturbance variable $w \in \mathbb{R}^{n_{w}}$ related to consumer demand for water in the WSS ( $n_{w}$ equals with $\left.n_{d}\right)$, JWSS represents the objective function for the MPC method of WSS.

In the WSS, the integrated control performances normally involve: (i) Minimizing energy consumption; (ii) maintain ecological requirement for the supply rivers; (iii) balancing water usage to sustain water resources; (iv) emergency handling to maintain a certain amount of water in the tank; and (v) smoothness management for water gates to protect assets [27,41]:

$$
J_{W S S}(x, u, w)=a_{\text {energy }} J_{\text {energy }}+a_{\text {ecol }} J_{\text {ecol }}+a_{\text {balance }} J_{\text {balance }}+a_{\text {safety }} J_{\text {safety }}+a_{\text {smooth }} J_{\text {smooth }}
$$

The development of MPC controller for the UDS is based on solving the following optimization problem $[9,27,28,39]$ :

$$
\begin{gathered}
\min _{x, u} J_{U D S}(x, u, w) \\
\text { s.t. } \\
x(t+1)=f_{U D S}(x(t), u(t), w(t))
\end{gathered}
$$

where the state variable $\mathrm{x} \in \mathbb{R}^{n_{x}}$ represents both tank volumes and TSS mass in UDS ( $n_{x}$ equals with $2 *$ $\left.n_{m}\right) ; u \in \mathbb{R}^{n_{u}}$ is the control variable manipulated flow through the available actuators for UDS ( $n_{u}$ equals with $\left.0.5 * n_{t i}+0.5 * n_{t o}\right)$; the disturbance variable $w$ is not considered for the UDS, JUDS represents the objective function for the MPC method of UDS.

Furthermore, in the UDS, five performance indexes are normally considered for the integrated MPC approach, which are: (i) CSO minimization; (ii) suspended solids discharges minimization; (iii) WWTP usage maximization; (iv) safety level maintenance for the detention tank; and (v) control variables smoothness:

$$
J_{U D S}(x, u, w)=a_{c s o} J_{c s o}+a_{\text {mass }} J_{\text {mass }}+a_{w w t p} J_{w w t p}+a_{\text {safe }} J_{\text {safe }}+a_{\text {smoot }} J_{\text {smoot }}
$$


In Equations (6) and (8), $a \in \mathbb{R}^{+}$are the control weights that can be tuned by the system manager according to operational priorities; JWSS and JUDS are considered independently by different MPC controllers.

It should be noted that $a_{\text {energy }}, a_{\text {ecol }}, a_{\text {balance, }} a_{\text {safety }}, a_{\text {smooth }}, a_{c s o}, a_{\text {mass }}, a_{w w t p}, a_{\text {safe }}$, and $a_{\text {smoot }}$ are weights which decide priorities of the items appearing in the objective functions. In reality, the weights are established by the water authorities. In this paper, the following weights in Table 1 are used, which show higher importance for energy and water usage balance in WSS and CSO minimization in the UDS:

Table 1. Weights configuration for objective functions

\begin{tabular}{ccccc}
\hline \multicolumn{5}{c}{ Water Supply System } \\
\hline$a_{\text {energy }}$ & $a_{\text {ecol }}$ & $a_{\text {balance }}$ & $a_{\text {safety }}$ & $a_{\text {smooth }}$ \\
\hline $\mathbf{1 0 0}$ & 100 & 200 & 1 & 1 \\
\hline \multicolumn{5}{c}{ Urban Drainage System } \\
\hline $\boldsymbol{a}_{\text {cso }}$ & $a_{\text {mass }}$ & $a_{\text {wwtp }}$ & $a_{\text {safe }}$ & $a_{\text {smoot }}$ \\
\hline $\mathbf{1 0 0}$ & 1 & 100 & 1 & 1 \\
\hline
\end{tabular}

For the MPC applications in UWC, different sampling times $\Delta t$ are defined depending on the system dynamics. Within this interval, the MPC receives required state estimation from the measurements obtained by the sensors, generating the optimal control actions, and afterwards sending them as set-points to the controlled actuators. In the WSS, the $\Delta t$ is normally set to $1 \mathrm{~h}$ with a predict/control horizon of 24-48 h; while the UDS is usually operated with a 30-60 min horizon, and control intervals of 5-10 min.

Based on the internal model and control formulation, the MPC approach is defined. In the case of MPC with linear prediction models, constraints, and quadratic performance indexes, the MPC approach can be translated into a quadratic programming $(\mathrm{QP})$ problem, which can be solved using MATLAB and the QP solver of TOMLAB [42], a free toolbox for academic usage. In term of MPC with nonlinearity at the prediction model, constraints or control formulations, GAMS optimization environment [43] with CPLEX solver [44] appears as a good option due to the combination benefits in term of modelling difficulty, economic cost, and computational efficiency.

\section{Case Studies}

\subsection{Barcelona Pilot WSS}

The Barcelona WSS is located within the Catalonia internal basins, which supplies drinking water to approximately 5.5 million people. The main water resources are extracted from two rivers, Llobregat and Ter, which are limited by the reduced amount of rain in the Mediterranean area. Since 1980, there have been increasing water scarcity problems in this area. Figure 4 shows one part of the aggregated Barcelona WSS network, where the Llobregat and Ter are the main water sources and the drinking water is transported through the pumping network. Water tanks are shown in light blue $(T 1, T 2, \ldots$ T7), pumps are in yellow, and the aggregated demands, inside which are also district metered areas (DMAs), are shown in dark blue $(D 0, D 1, \ldots D 7)$.

According to the definitions of CPS for UWC, the Barcelona WSS can be considered as two subsystems. The two rivers (simplified as two water sources in Figure 4) represent the DWTP subsystem, whose objectives are to maintain ecological requirements for the rivers and the sustainability of water resources ( balance $_{\text {) }}$ through balancing water extraction from the two rivers. The transportation network inside the city (Figure 4) can be considered as the DWDDS subsystem, whose management objectives are to satisfy the water consumers using minimal energy cost $\left(J_{\text {energy }}\right)$ and safe storage inside the tank $\left(J_{\text {safety }}\right)$. 
Several water production plants located upstream along the Ter river make the treatment process more complex and economically demanding. Thus, water from the Llobregat river can be obtained by the water distribution managers at a lower cost than that from the Ter. Considering the control of the DWDDS subsystem, most of the required water should come from the cheaper source to satisfy the minimal cost objective. However, taking into account the river ecological levels required by the DWTP subsystem, different management strategies are required. According to the CPS-based management approach, the DWDDS and the DWTP subsystems should interoperate by means of supervision control through integrated MPC approach, which can achieve optimal performance considering objectives for all of the subsystems. To validate the proposed strategy, the following two scenarios are considered:

Scenario 1: Manage the Barcelona WSS using separate control algorithms;

Scenario 2: Manage the Barcelona WSS under CPS-based structure, considering supervision control and interoperability of subsystems by integrated MPC optimization algorithm.

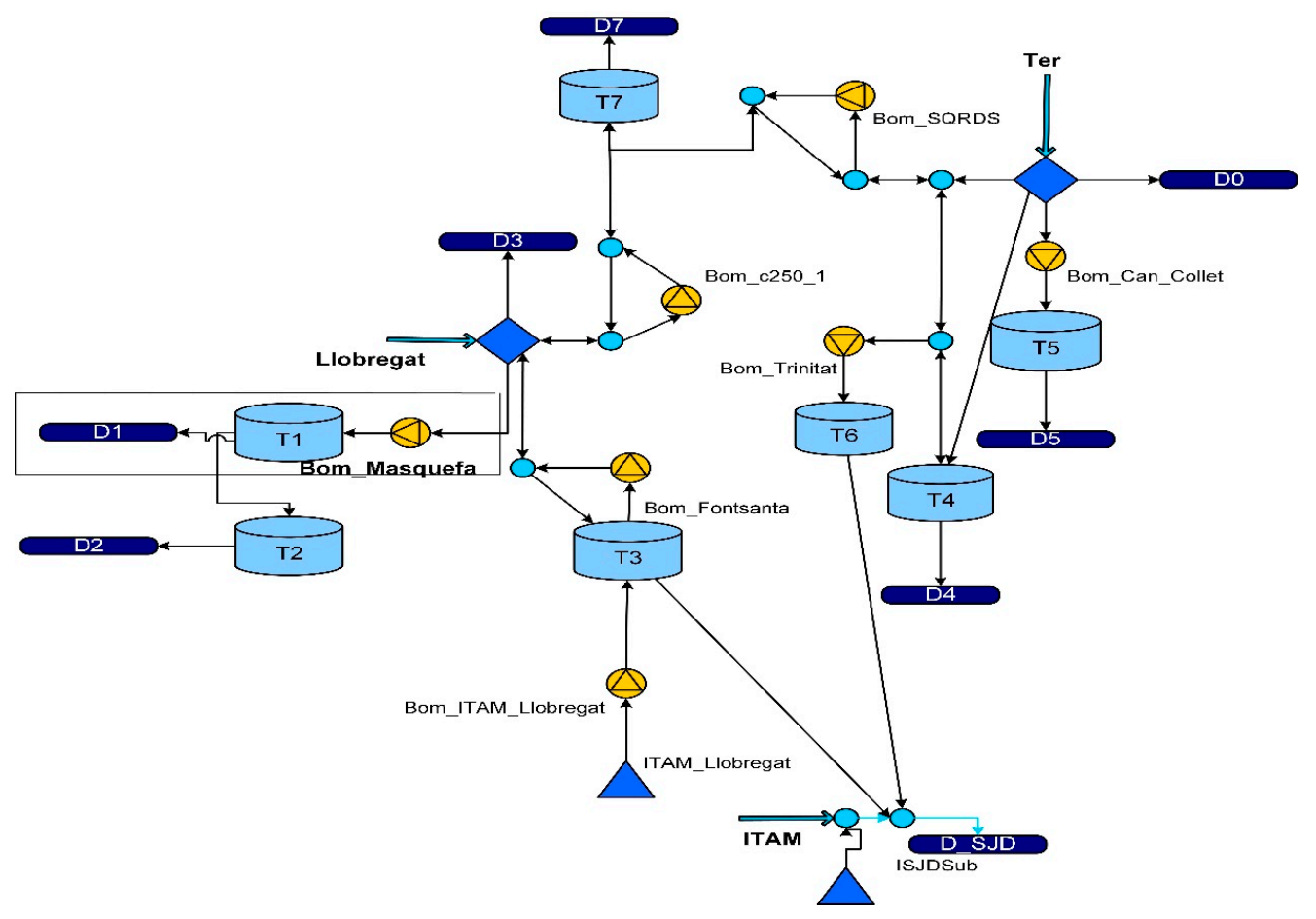

Figure 4. Barcelona WSS.

The integrated MPC optimization was implemented using MATLAB and the QP solver of TOMLAB. A digital representation of the Barcelona WSS has been developed using MATLAB/SIMULINK (Figure 5) in order to simulate the physical network and evaluate the MPC controller in virtual reality. The optimization and simulation are working interactively by communicating mutual information automatically, which is achieved by the two S-functions in SIMULINK S-controller and S-simulator, where they produce, transfer and receive useful information in a closed loop [31]. The sampling time $\Delta t$ for this MPC is $1 \mathrm{~h}$ with a prediction/control horizon of $24 \mathrm{~h}$ and simulation period of 6 days. 


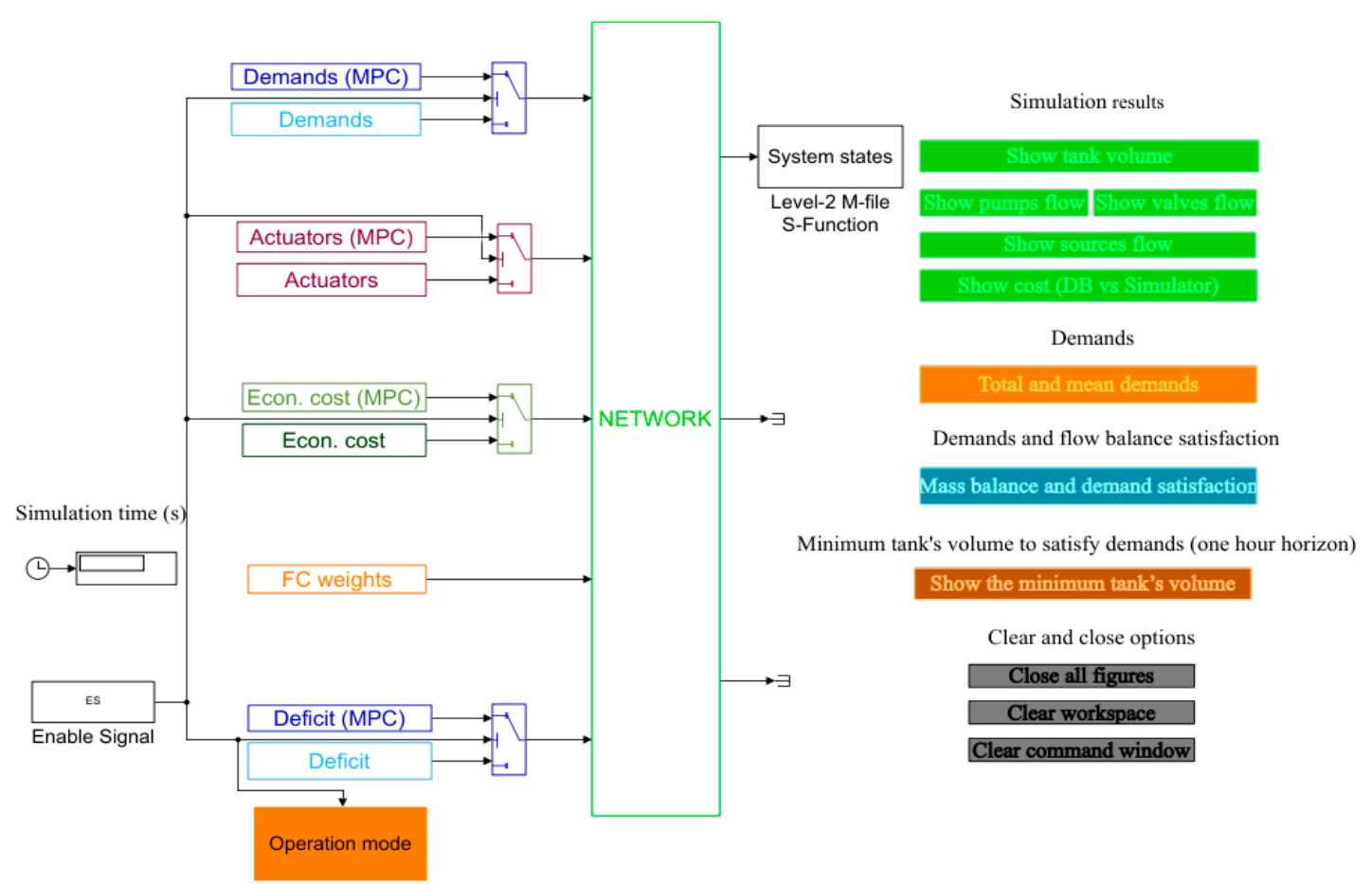

Figure 5. Digital representation of Barcelona WSS using MATLAB/SIMULINK.

\subsubsection{Ecological Objective}

Figure 6 illustrates the water resources required by the DWDDS subsystem from both the Ter and Llobregat rivers in Scenario 1. Considering the cheaper price, more than $80 \%$ of the water comes from the Llobregat, which results in ecological problems for the DWTP subsystem, as illustrated in Figure 7. The red line in Figure 7 represents the minimal river flow $\left(0.95 \mathrm{~m}^{3} / \mathrm{s}\right)$ should be maintained due to ecological requirement, the blue line is the real river flow at Llobregat. Obviously, ecological problem happens frequently at this scenario.

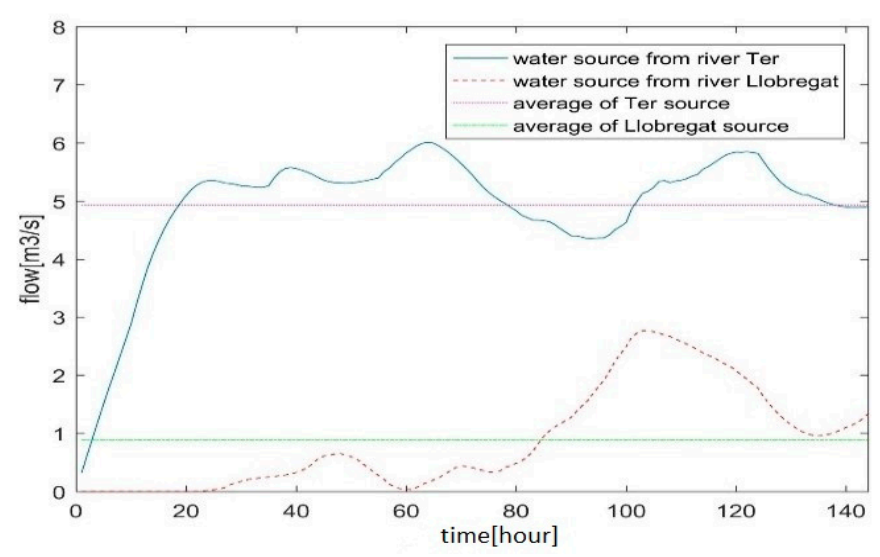

Figure 6. Water source requirement from two rivers in Scenario 1. 


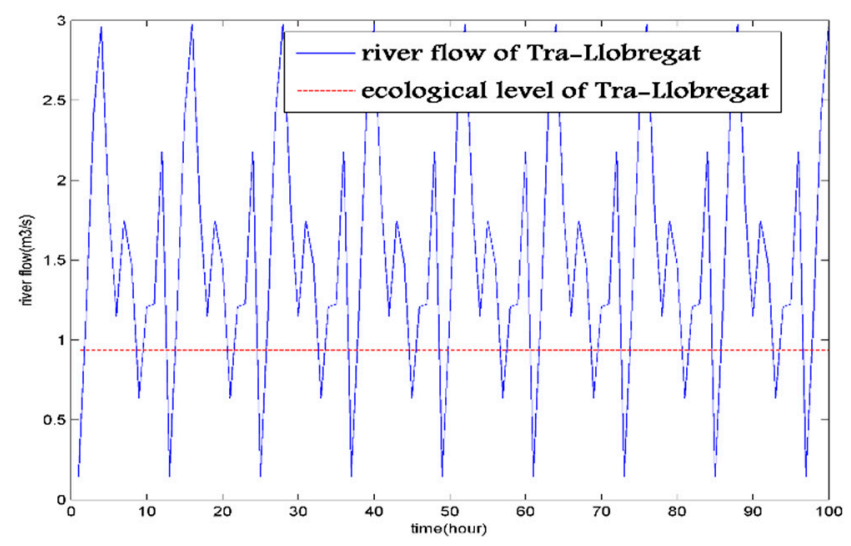

Figure 7. Ecological situation at river Llobregat in Scenario 1.

Figure 8 illustrates water resources required by the DWDDS subsystem of the two rivers under the CPS-based management structure, where the objective requirements from the DWTP subsystem are also considered and more balance extraction from the two rivers are achieved. Correspondingly, ecological problem at river Llobregat has been eliminated, as shown at Figure 9.

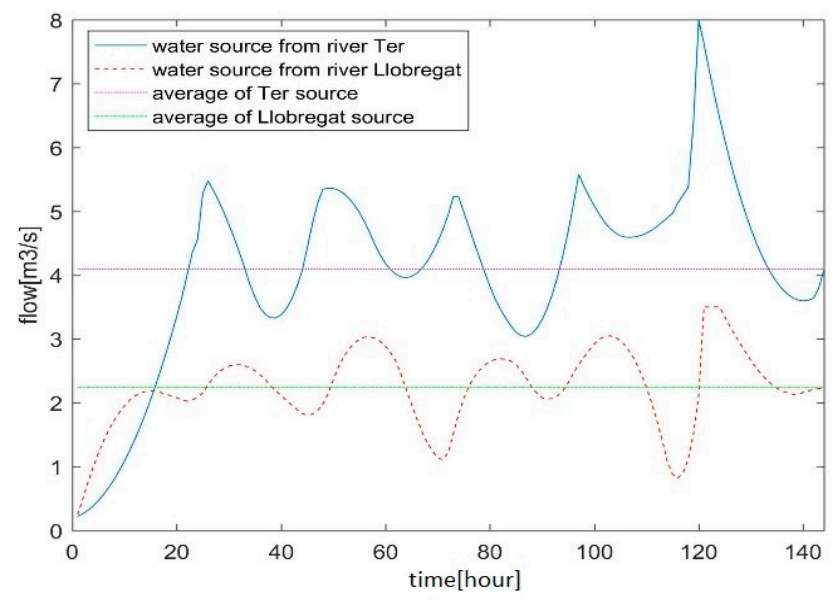

Figure 8. Water source requirement from two rivers in Scenario 2.

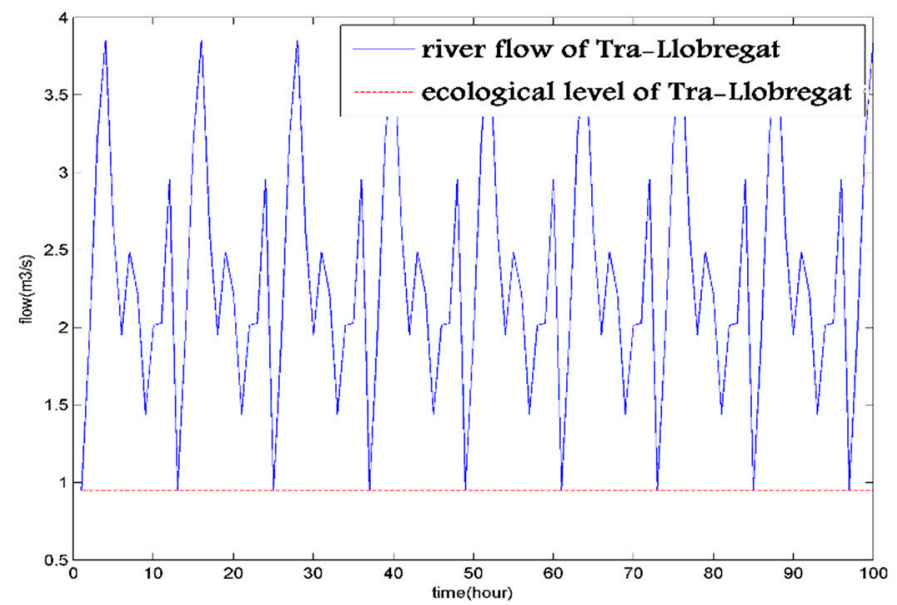

Figure 9. Ecological situation at river Llobregat in Scenario 2.

More detailed results for Scenario 2 are presented in Table 2, where the Source, Demand, Balance, and Ecological represent water supply capacities of the two rivers, water consumption associated to each river, available water sources in the rivers after meeting water demand, and the ecological 
requirement from the two rivers, respectively. Besides, the Supplying means the water supply abilities in days of the Barcelona WSS before meeting deficit problem at the hypothesis with no rain and no water flow in from outside. From Table 2, a conclusion can be obtained, which is the supervision control and interoperability of subsystems in the CPS-based management structure can prevent the water scarcity problem and ensures that the rivers can supply water for more than 107 days before meeting any ecological problems. This improves the reliability of the ecological management of the rivers and the sustainable usage of the water resources.

Table 2. Ecological balancing comparison between Scenarios 1 and 2.

\begin{tabular}{|c|c|c|c|c|c|}
\hline \multicolumn{6}{|c|}{ CPS-Based Management Approach } \\
\hline & Source $/ \mathrm{m}^{3}$ & Demand $/ \mathrm{m}^{3}$ & Balance $/ \mathrm{m}^{3}$ & Ecological $/ \mathrm{m}^{3}$ & Supplying/days \\
\hline Llobregat & 2025 & 1205 & 820 & 715 & \multirow{2}{*}{258} \\
\hline Ter & 4027 & 2214 & 1813 & 1738 & \\
\hline \multicolumn{6}{|c|}{ Separate Control Scheme } \\
\hline & Source $/ \mathrm{m}^{3}$ & Demand $/ \mathrm{m}^{3}$ & Balance $/ \mathrm{m}^{3}$ & Ecological $/ \mathrm{m}^{3}$ & Supplying/days \\
\hline Llobregat & 2025 & 25 & 2000 & 715 & \multirow{2}{*}{151} \\
\hline Ter & 4027 & 3394 & 633 & 1738 & \\
\hline
\end{tabular}

\subsubsection{Economic Objective}

Furthermore, Figure 10 compares the flow of one pump (Bom_Masquefa, connected with tank $\mathrm{T} 1$, as marked by a rectangular frame in Figure 4) and its electricity cost. The blue line at this figure represents water flow pumped by Bom_Masquefa. The red line is the electricity price at different hours. The efficiency cost is for the qualitative comparison only due to the requirement from the electricity company. Considering the confidential requirement form the water companies, the numbers of the price are modified without unit. From this plot, we can see that MPC forces the pump to work more when the electricity is cheaper and less when the electricity is more expensive. Using this optimal strategy, the objectives in the DWDDS subsystem have also been satisfied, with energy savings of up to $5 \%$ (4.1 GWh/year) and energy cost savings of up to $20 \%$ (0.4 M€/year).

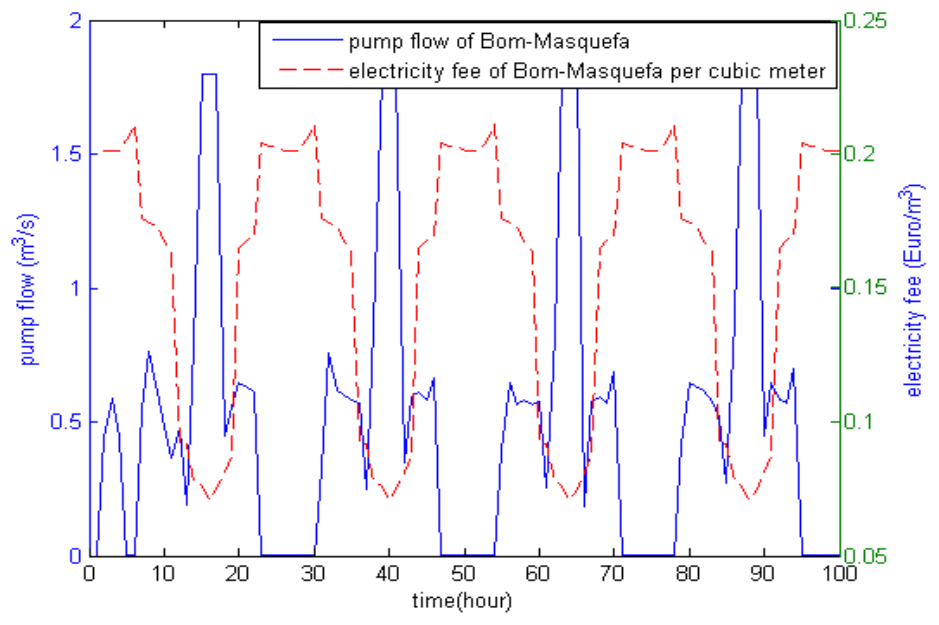

Figure 10. Electricity cost using CPS-based management approach.

\subsection{Badalona Pilot UDS}

Badalona is located in Eastern Catalonia (Spain) and is part of the Barcelona metropolitan area. A population of around 215,000 inhabitants lives within an area of $21.2 \mathrm{~km}^{2}$. Figure 11 presents a simplified model of the Badalona UDS, including one detention tank T1 served by two upstream 
catchments VT1 and VT3, which send water to T1 through gates G1 and G2. Wastewater in T1 is extracted by pump $P$ and sent to the WWTP for treatment. However, CSO can occur when the WWTP capacity is exceeded.

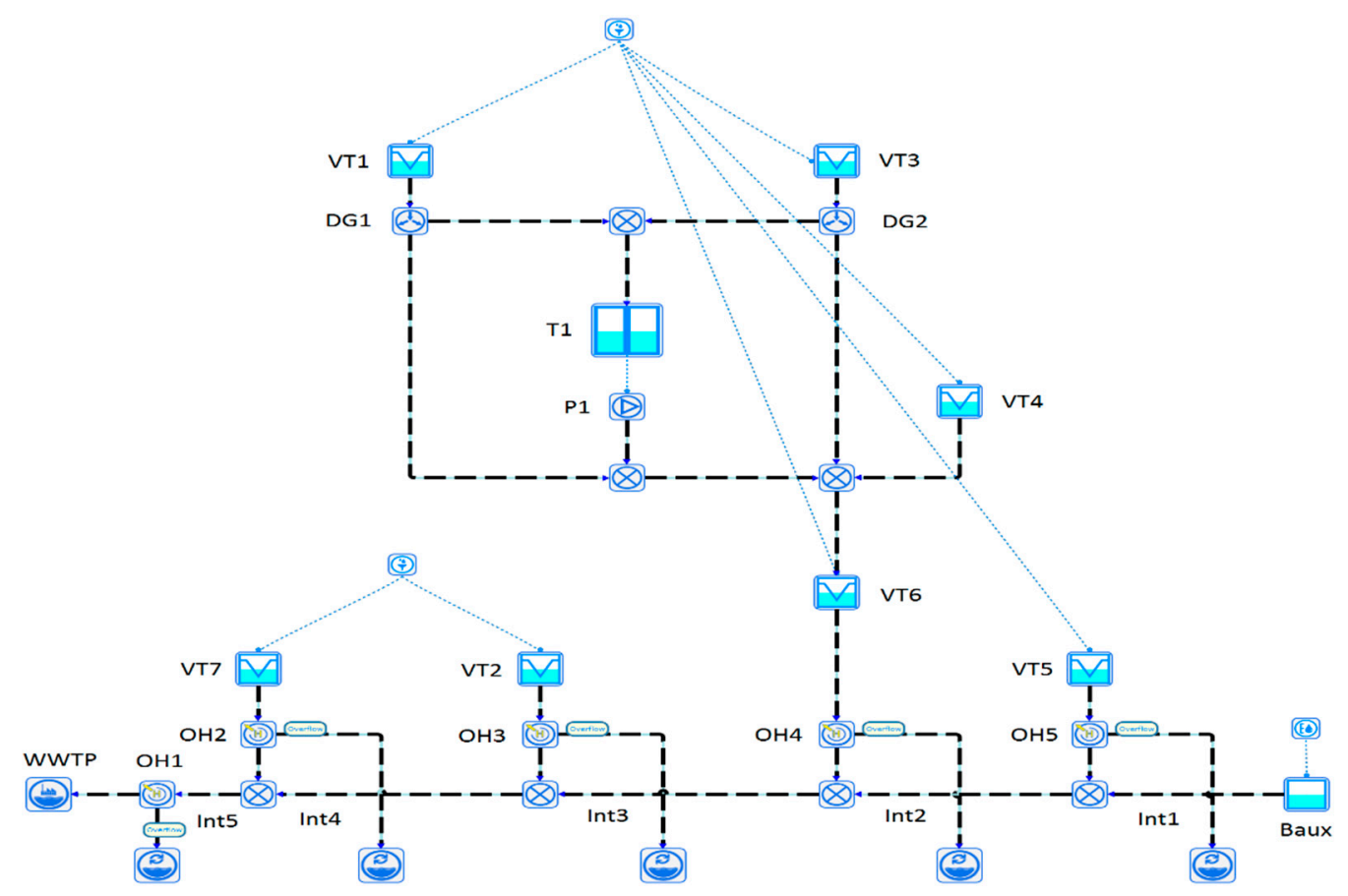

Figure 11. Badalona urban drainage system (UDS).

According to the definitions of CPS for UWC, in the Badalona UDS, the WSCS and WWTP are considered as two subsystems. Generally, the treatment capacity of a WWTP varies with time, depending on several factors related to the operational status of the physical and biological processes in the plant. However, when the systems are operated separately, the WSCS subsystem usually considers the WWTP capacity to be constant, equal to the nominal plant capacity. The timely notification of the real plant capacity and its predicted values for a control horizon, as constraints for the WSCS water detention and diversion optimization, can significantly improve the ability of UDS to prevent CSO. In order to validate the CSP-based framework, two different scenarios are defined:

Scenario 1: Optimization of the WSCS subsystem separately with a nominal WWTP capacity.

Scenario 2: Supervision control and Interoperability of the WSCS and WWTP subsystems through integrated MPC optimization considering real-time capacity of WWTP and global optimization objectives.

The Equation (4) in the MPC internal model for the UDS includes coefficient $e$ which needs to be calibrated in order to obtain the best performance of this model. The calibration processes can be referred from $[9,33]$. The $e$ being used in this case study is 0.25 .

Considering nonlinearity of the MPC problem of UDS, the MPC optimization has been applied through MATLAB and the GAMS optimization environment [43] using internal models. A digital representation of the Badalona UDS has been developed through SWMM in order to simulate the physical network and evaluate the MPC controller. The communication between optimization and simulation is based on MATLAB script environment in text-editing routines to manipulate the simulator files automatically at each iteration $[45,46]$. The sampling time $\Delta t$ for this MPC is 5 min with a prediction/control horizon of $30 \mathrm{~min}$ and simulation period of 6 days.

Figure 12 compares the mixed sewage water sent from the WSCS to the WWTP for treatment in the form of water flow. The yellow dashed line is the nominal constant WWTP capacity used for Scenario 1, which is $1.6 \mathrm{l} / \mathrm{s}$; the green dash-dot line represents the real-time WWTP capacity for Scenario 
2. The blue line is the flow being sent to the WWTP when separate control is applied, and the red crosses denote the flow sent from the WSCS to the WWTP by the CPS control approach.

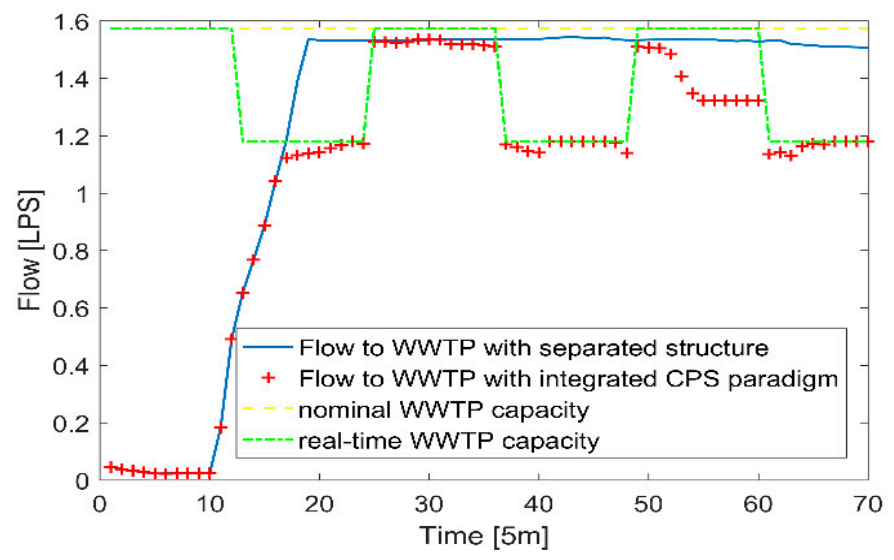

Figure 12. Comparisons of the flow from WSCS to WWTP in Scenario 1 (blue) and Scenario 2 (red).

In the integrated MPC optimization approach, the WWTP capacity prediction has been integrated and considered as a real-time parameter during the optimization process. The real treatment capacity of the WWTP is sent to the MPC-based controller, allowing the working schedule of the detention tank and other elements of the UDS to be adjusted to minimize CSO.

In the separate management algorithm, the WSCS continues to send the same amount of wastewater to the WWTP, regardless of whether the capacity has been enlarged or reduced. This does not allow the UDS to take full advantage of the WWTP capacity.

This comparison confirms that, after applying CPS-based management framework, the water flow being sent to the WWTP always considers the real treatment capacity, whereas the water flow produced by separate control may exceed the treatment capacity of the WWTP, resulting in CSO being released directly to the environment without treatment.

Figure 13 compares the CSO produced by the two different control algorithms. The CSO produced by the CPS-based supervision paradigm has been reduced by more than $32 \%$ compared with the CSO produced by the separate control approach.

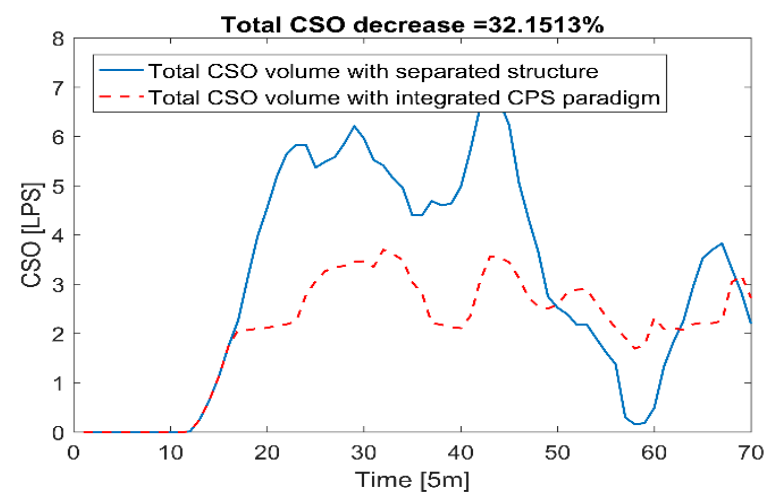

Figure 13. CSO comparisons of Scenario 1 (blue) and Scenario 2 (red).

\section{Discussion}

This paper has analyzed the operation of UWC under the CPS framework and demonstrated some of the key technical features of CPS applied to UWC systems. Clear definitions of how UWC can be considered as a CPS have been provided. A multilayer CPS-based supervision management structure was proposed in which the physical UWC and its digital counterpart were conceptually divided into four layers (Supervision\&Control Layer, Scheduling Layer, Digital Twin Layer, Water Users, and 
Environment Layer). The information flows have also been defined to interact with each layer of the supervision structure. Moreover, the supervision control and the interoperability of subsystems in the context of UWC systems has been addressed. An integrated MPC-based optimization algorithm was implemented to demonstrate the advantages of supervision control and interoperability of two (or more than two) subsystems in the water cycle. The application results confirm that, after operating the UWC using the CPS conception, globally optimal strategies were obtained, offering significant improvements in resource sustainability and environmental protection in the overall UWC.

In order to continue exploring the management improvements generated by digitalization and modelling frameworks based on the CPS concept to the UWC sector, more deep research in about detailed interconnected digital twins, interfacing with real systems to provide RTC features will be presented in future. Moreover, theoretical innovations about the MPC approach considering the stochastic characteristics of UWC will also be considered.

Author Contributions: C.S. contributed to the subject of research, the development of the CPS framework, system identification of MPC, simulation of case studies and the writing of the paper. V.P. contributed in the formulation of MPC optimizer, definition of the cost functions and the manuscript review. G.C. collaborated in the conceptual modelling, digital representative development and simulation in the case studies, as well as the manuscript review. All authors have read and agreed to the published version of the manuscript.

Funding: This work is partially funded by grants LIFE EFFIDRAIN LIFE14 ENV/ES/00080, EFFINET FP7-ICT-2011-8-318556, internal project of TWINs, and also supported by the Spanish State Research Agency through the María de Maeztu Seal of Excellence to IRI (MDM-2016-0656).

Acknowledgments: The support of the Barcelona City Council (Ajuntament de Barcelona) and the Badalona City Council (Ajuntament de Badalona) for the case studies are gratefully acknowledged.

Conflicts of Interest: The authors declare no conflict of interest.

\section{Acronyms}

$\begin{array}{ll}\text { UWC } & \text { Urban Water Cycle } \\ \text { WSS } & \text { Water Supply System } \\ \text { UDS } & \text { Urban Drainage System } \\ \text { CPS } & \text { Cyber-physical System } \\ \text { MPC } & \text { Model Predictive Control } \\ \text { WWTP } & \text { Wastewater Treatment Plant } \\ \text { EPA } & \text { Environmental Protection Agency } \\ \text { SWMM } & \text { Storm Water Management Model } \\ \text { DWTP } & \text { Drinking Water Treatment Plant } \\ \text { DWDDS } & \text { Drinking Water Delivery and Distribution system } \\ \text { WSCS } & \text { Wastewater and Stormwater Collection Systems } \\ \text { WWTP } & \text { Wastewater Treatment Plants } \\ \text { CSO } & \text { Combined Sewer Overflow } \\ \text { ICT } & \text { Information and Communication Technologies } \\ \text { AMR } & \text { Automatic Meter Reading } \\ \text { SCADA } & \text { Supervisory Control And Data Acquisition } \\ \text { RTC } & \text { Real-Time Control }\end{array}$

\section{References}

1. Nikolopoulos, D.; Makropoulous, C.; Kalogeras, D.; Monokrousou, K.; Tsoukalas, I. Developing a stress-testing platform for cyber-physical water infrastructure. In Proceedings of the 4th International Workshop on Cyber-Physical Systems for Smart Water Networks, Porto, Portugal, 10-13 April 2018.

2. Imen, S.; Chang, N. Developing a cyber-physical system for smart and sustainable drinking water infrastructure management. In Proceedings of the IEEE 13th International Conference on Networking, Sensing, and Control (ICNSC), Mexico, Mexico, 28-30 April 2016.

3. Gasperi, J.; Garnaud, S.; Rocher, V.; Moilleron, R. Priority pollutants in wastewater and combined sewer overflow. J. Sci. Total Environ. 2008, 407, 263-272. [CrossRef] [PubMed] 
4. Bunn, S.; Wooley, X. Derceto: An on-line pump schedule optimisation system. In Proceedings of the New Zealand Water and Wastes Association Annual Conference, Wellington, New Zealand, 19-21 September 2001; Available online: http://www.derceto.com (accessed on 8 January 2019).

5. Bou, V.; Martinez, F.; Conejo, P. SCA-Red: A general purpose SCADA application for taking decision in real time with the aid of a hydraulic model. In Proceedings of the ASCE, Water Distribution Systems Analysis Symposium, Cincinnati, OH, USA, 27-30 August 2006; Available online: http://www.iiama.upv.es (accessed on 8 January 2019).

6. Rao, Z.; Wicks, J.; West, S. Encoms: An Energy Cost Minimization System for Real-Time, Operational Control for Water Distribution Networks. In Proceedings of the 8th International Conference on Computing and Control for the Water Industry, Exeter, UK, 1-4 September 2019; pp. 85-90. Available online: http: //www.halcrow.com (accessed on 8 January 2019).

7. Lin, J. Agent-Based Analysis and Mitigation of Failure for Cyber-Physical Systems. Ph.D. Thesis, Missouri University of Science and Technology, Rolla, MO, USA, 2011. Available online: http://scholarsmine.mst.edu/ doctoral_dissertations/1909 (accessed on 6 October 2019).

8. Joseph, B.; Ocampo-Mart'inez, C.; Cembrano, G. Hybrid modelling and receding horizon control of sewer networks. Water Resour. Res. 2014, 50, 8497-8514. [CrossRef]

9. Sun, C.C.; Joseph-Duran, B.; Maruejouls, T.; Cembrano, G.; Meseguer, J.; Puig, V.; Litrico, X. Real-time control-oriented quality modelling in combined urban drainage networks. In Proceedings of the IFAC 2017 World Congress, Toulouse, France, 9-14 July 2017; pp. 4002-4007.

10. Zhaohui, W.; Houbing, S.; David, W.W.; Keat, G.O.; Pengfei, X.; Qing, Y.; Xianming, S. Cyber-physical systems for water sustainability: Challenges and opportunities. IEEE Commun. Mag. 2015, 53, $216-222$.

11. Wastewater Management: Controlling and Abating Combined Sewer Overflows; Office of Inspector General Evaluation Report; U.S. Environmental Protection Agency: Washington, DC, USA, 2006. Available online: https://www.epa.gov/sites/production/files/2015-12/documents/csofinal.pdf (accessed on 10 August 2019).

12. Fanlin, M.; Guangtao, F.; David, B. Cost-effective river water quality management using integrated real-time control technology. Environ. Sci. Technol. 2017, 51, 9876-9886.

13. Tu, M.C.; Traver, R.G. Optimal comfiguration of an underdrain delivery system for stormwater infiltration trench. J. Irrig. Drain. Eng. 2019, 145. [CrossRef]

14. Sanislav, T.; Miclea, L. Cyber-Physical Systems-Concept, Challenges and Research Areas. Control Eng. Appl. Informa. 2012, 14, 28-33.

15. Skorobogatjko, A.; Romanovs, A.; Kunicina, N. State of the Art in the Healthcare Cyber-Physical Systems. Inf. Technol. Manag. Sci. 2014, 17, 126-131.

16. Cyber-Physical Systems Week. Available online: http://www.cpsweek.org/ (accessed on 1 September 2019).

17. Wang, Y.B.; Vuran, M.C.; Goddard, S. Cyber-Physical Systems in Industrial Process Control; University of Nebraska-Lincoln: Lincoln, NE, USA, 2008; Available online: http://sigbed.seas.upenn.edu/archives/2008-01/ Wang.pdf (accessed on 10 August 2019).

18. Greer, C.; Burns, M.; Wollman, D.; Griffor, E. Cyber-Physical Systems and Internet of Things; NIST Special Publication: Gaithersburg, MD, USA, 2019.

19. Taormina, R.; Galelli, S.; Tippenhauer, N.O.; Salomons, E.; Ostfeld, A. Characterizing Cyber-Physical Attacks on Water Distribution Systems. J. Water Resour. Plan. Manag. 2017, 143, 1-12. [CrossRef]

20. Uhlemann, T.H.-J.; Lehmann, C.; Steinhilper, R. The Digital Twin: Realizing the Cyber-Physical Production System for Industry 4.0. In Proceedings of the 24th CIRP Conference on Life Cycle Engineering, Kamakura, Japan, 8-10 March 2017; Volume 61, pp. 335-340.

21. Huber, W.C.; Dickinson, R.E. Storm Water Management Model, Version 4: User's Manual; U.S. Environmental Protection Agenc: Athens, GA, USA, 1988.

22. DHI, Danish Hydraulic Institute. MIKE URBAN. 2007. Available online: https://www.mikepoweredbydhi. com/products/mike-urban (accessed on 24 October 2018).

23. Rossman, L.A. Epanet 2.0 Users Manual; EPA/600/R-00/057; Environmental Protection Agency: Cincinnati, $\mathrm{OH}, \mathrm{USA}, 2000$.

24. Seggelke, K.; Löwe, R.; Beeneken, T.; Fuchs, L. Implementation of an integrated real-time control system of sewer system and waste water treatment plant in the city of Wilhelmshaven. Urban Water J. 2013, 10, 330-341. [CrossRef] 
25. Kerkez, B.; Gruden, C.; Lewis, M.; Montestruque, L.; Quigley, M.; Wong, B.; Bedig, A.; Kertesz, R.; Braun, T.; Cadwalader, O.; et al. Smarter Stormwater Systems. Environ. Sci. Technol. 2016, 50, 7267-7273. [CrossRef] [PubMed]

26. Puig, V.; Cembrano, G.; Romera, J.; Quevedo, J.; Aznar, B.; Ramón, G.; Cabot, J. Predictive optimal control of sewer networks using CORAL tool: Application to Riera Blanca Catchment in Barcelona. Water Sci. Technol. 2009, 60, 869-878. [CrossRef] [PubMed]

27. Sun, C.C.; Puig, V.; Cembrano, G. Temporal multi-level coordination techniques oriented to regional water network: Application to the Catalunya case study. J. Hydroinform. 2014, 16, 952-970. [CrossRef]

28. Ocampo-Martinez, C.; Puig, V.; Cembrano, G.; Quevedo, J. Application of predictive control strategies to the management of complex networks in the urban water cycle. IEEE Control Syst. Mag. 2013, 33, 15-45.

29. Brdys, M.A.; Ulanicki, B. Operational Control of Water Systems: Structures, Algorithms and Applications; UK Prentice Hall International: Hertfordshire, UK, 1994.

30. Overloop, P.V. Model Predictive Control on Open Water Systems; Delft University Press: Delft, The Netherlands, 2006.

31. Sun, C.C.; Puig, V.; Cembrano, G. Integrated simulation and optimization scheme of real-time large-scale water supply network: Applied to Catalunya case study. Simulation 2015, 91, 59-70. [CrossRef]

32. Sun, C.C.; Puig, V.; Cembrano, G. Combining CSP and MPC for the operational control of water networks: Application to the Richmond case study. In Proceedings of the 19th IFAC World Congress, Cape Town, South Africa, 24-29 August 2014; pp. 6246-6251.

33. Sun, C.C.; Joseph, B.; Maruejouls, T.; Cembrano, G.; Muñoz, E.; Meseguer, J.; Montserrat, A.; Sampe, S.; Puig, V.; Litrico, X. Efficient integrated model predictive control of urban drainage systems using simplified conceptual quality models. In Proceedings of the 14th IWA/IAHR International Conference on Urban Drainage, Prague, Czech Republic, 10-15 September 2017; pp. 1848-1855.

34. Sun, C.C.; Cembrano, G.; Puig, V.; Meseguer, J. Cyber-physical systems for real-time management in the urban water cycle. In Proceedings of the 4th International Workshop on Cyber-Physical Systems for Smart Water Networks, Porto, Portugal, 10-13 April 2018; pp. 5-8.

35. Sun, C.C.; Joseph, B.; Cembrano, G.; Puig, V.; Meseguer, J. Advanced integrated real-time control of combined urban drainage systems using MPC: Badalona case study. In Proceedings of the 13th International Conference on Hydroinformatics, Palermo, Italy, 1-6 June 2018; pp. 2033-2041.

36. Sun, C.C.; Morley, M.; Savic, D.; Puig, V.; Cembrano, G.; Zhang, Z. Combining model predictive control with constraint-satisfaction formulation for the operative pumping control in water networks. In Proceedings of the 13th Computing and Control for the Water Industry Conference, Leicester, UK, 2-4 September 2015; pp. 963-972.

37. Sun, C.C.; Puig, V.; Cembrano, G. Multi-layer model predictive control of regional water networks: Application to the Catalunya case study. In Proceedings of the 52nd IEEE Conference on Decision and Control, Florence, Italy, 10-13 December 2013; pp. 7095-7100.

38. Sun, C.C.; Joseph, B.; Maruejouls, T.; Cembrano, G.; Muñoz, E.; Meseguer, J.; Montserrat, A.; Sampe, S.; Puig, V.; Litrico, X. Conceptual quality modelling and integrated control of combined urban drainage system. In Proceedings of the 12th IWA Conference on Instrumentation, Control and Automation, Quebec, QC, Canada, 11-14 June 2017; pp. 141-148.

39. Gelormino, M.; Ricker, N. Model-predictive control of a combined sewer system. Int. J. Control 1994, 59, 793-816. [CrossRef]

40. Cembrano, G.; Quevedo, J.; Salamero, M.; Puig, V.; Figueras, J.; Martí, J. Optimal control of urban drainage systems. A case study. Control Eng. Pract. 2004, 12, 1-9. [CrossRef]

41. Sun, C.C.; Puig, V.; Cembrano, G. Combining CSP and MPC for the operational control of water networks. Eng. Appl. Artif. Intell. 2016, 49, 126-140.

42. Holmström, K.; Edvall, M.M. The TOMLAB Optimization Environment. In Modeling Languages in Mathematical Optimization. Applied Optimization; Kallrath, J., Ed.; Springer: Boston, MA, USA, 2004; Volume 88.

43. Rosenthal, R. GAMS-A User's Guide, GAMS Development Corporation. 2013. Available online: http: //www.gams.com/help/topic/gams.doc/userguides/GAMSUsersGuide.pdf (accessed on 1 May 2018).

44. Rodríguez-Carbonell, E. Tutorial on CPLEX Linear Programming; Technical University of Catalunya: Barcelona, Spain, 2019. 
45. Joseph-Duran, B.; Meseguer, J.; Cembrano, G.; Maruejouls, T. Closed-loop simulation of real-time controllers for urban drainage systems using high resolution hydraulic simulators. In Proceedings of the 14th IWA/IAHR International Conference on Urban Drainage, Prague, Czech Republic, 10-15 September 2017.

46. Romero-Ben, L.; Sun, C.C.; Guasch-Palma, R.; Joseph, B.; Meseguer, J.; Cembrano, G.; Puig, V. A Feedback Simulation Procedure for Real-time Control of Urban Drainage Systems. In Proceedings of the 1st IFAC Workshop on Control Methods for Water Resource Systems, Delft, The Netherlands, 19-20 September 2019; Volume 52, pp. 101-106.

(C) 2020 by the authors. Licensee MDPI, Basel, Switzerland. This article is an open access article distributed under the terms and conditions of the Creative Commons Attribution (CC BY) license (http://creativecommons.org/licenses/by/4.0/). 